JOURNAL OF GEOPHYSICAL RESEARCH, VOL. 91, NO. B7, PAGES 7495-7503, JUNE 10, 1986

\title{
SHOCK WAVE EQUATION OF STATE OF ENSTATITE
}

\section{J. Peter Watt}

Department of Geology, Rensselaer Polytechnic Institute, Troy, New York

Thomas J. Ahrens

Seismological Laboratory, California Institute of Technology, Pasadena, California

Abstract. Shock compression data are reported for hot-pressed Bamble bronzite (En86) loaded to pressures between 104 and $161 \mathrm{GPa}$. When compared to earlier shock wave data on Engo at lower pressures and to static compression data, our data require the presence of a phase change. In P-p space the data yield two distinct trajectories, which cannot be explained by experimental error. The higher-density data, corrected for porosity and a small amount of metallic iron impurity, agree with a theoretical En 86 high-pressure phase Hugoniot calculated from static compression equation of state data for perovskite (pv) structure silicates when experimental errors and uncertainties in the equation of state parameters are considered. Al1 the En 86 data can be described by a calculated Hugoniot if the first pressure derivative of the $\mathrm{MgSiO}_{3}(\mathrm{pv})$ bulk modulus is taken as 4.5+1.0. Combining the present preferred data with recent shock wave data for single-crystal forsterite, we find that En 86 is slightly more dense than Fo86 at pressures above $110 \mathrm{GPa}$. Comparison of the forsterite and enstatite data with the Preliminary Reference Earth Model (PREM) lower mantle densities, with corrections applied for the higher shock temperatures relative to lower mantle temperatures, shows that PREM densities are satisfied by olivine or pyroxene stoichiometries with $\mathrm{Mg}$ mole fractions from 0.82 to 0.90 . These values are lower than estimates of 0.90 to 0.95 developed from extrapolating static compression data to lower mantle conditions.

\section{Introduction}

0 livines and pyroxenes are thought to be important constituents of the mantle, and much attention has been given to elucidation of their high-pressure properties. of particular interest in the lower mantle is the transformation of these minerals to high-pressure forms with a dense perovskite (pv) structure as seen in static compression studies [Liu, 1975, 1976a, b; Ito, 1977; Mao et a 1., 1977; Sawamoto, 1977; Yagi et al., 1977]. Shock compression experiments have also shown indications of the existence of highpressure phases above $70 \mathrm{GPa}$ in olivines [Trunin et a1., 1965; McQueen et a1., 1967; McQueen, 1968; Ahrens and Petersen, 1969; Ahrens et a l., 1971; Jackson and Ahrens, 1979; Syono et a1., $1981 \mathrm{a}$; Watt and Ahrens, 1983] and pyroxenes [Trunin et a1., 1965; McQueen et a1., 1967; McQueen,

Copyright 1986 by the American Geophysical Union.

Paper number 4B5042.

$0148-0227 / 86 / 004 \mathrm{~B}-5042 \$ 05.00$
1968; Ahrens and Gaffney, 1971; Simakov and Trunin, 1973; Jeanloz and Ahrens, 1977].

Identification of the high-pressure products in shock wave experiments, however, is complicated by the difficulty in recovering samples of the high-pressure product that are metastable upon unloading from peak shock pressures [e.g., Jeanloz et a 1., 1977; Jeanloz, 1980; and Syono et a 1., 1981]. Syono et a1. [1981b] studied recovery products of single-crystal forsterite shocked between 78 and $92 \mathrm{GPa}$ and identified precipitates of $\mathrm{MgO}$ and glassy regions with approximately $\mathrm{MgSiO}_{3}$ composition and interpreted the results as evidence for formation of $\mathrm{MgSiO}_{3}(\mathrm{pv})$ and $\mathrm{MgO}$ at high pressure, although incongruent melting to form $\mathrm{MgO}$ crystals and $\mathrm{MgSiO}_{3}$ was not ruled out. Jakubith and Seide1 [1982] shocked an omphacitic eclogite and identified $\mathrm{MgSiO}_{3}(\mathrm{pv})$ in the $X$ rayed recovery product.

Because pyroxenes should form only a perovskite structure high-pressure phase rather than $(\mathrm{Mg}, \mathrm{Fe}) \mathrm{O}+(\mathrm{Mg}, \mathrm{Fe}) \mathrm{SiO}_{3}(\mathrm{pv})$ as in olivines, shock wave studies of pyroxenes can provide a more direct test of the compatibility of high-pressure dynamic properties and properties measured in static compression experiments.

Previous shock wave work on pyroxenes has used natural and synthetic samples with a range of composition and porosity, thus complicating data interpretation. Trunin et a1. [1965] investigated a pyroxenite ( $95 \%$ En $85 \mathrm{Fs}_{15}, 3 \%$ Fog $\mathrm{Fa}_{10}, 2 \%$ $\mathrm{An}_{60} \mathrm{Ab}_{40}$ ), McQueen et al. [1967] studied two bronzitites ( $92 \%$ En $90 \mathrm{Fs}_{10}, 4 \% \mathrm{An}_{80} \mathrm{Ab}_{20}, 2 \%$ hornblende; $94 \%$ EngoFs 10 , $2 \%$ olivine, $4 \%$ hornblende), McQueen [1968] studied $E_{100}$ with varying porosity, Simakov and Trunin [1973] measured four samples of $E_{100}$ (two natura1, two ceramic), all of which were porous, and Ahrens and Gaffney [1971] and Jeanloz and Ahrens [1977] studied Bamble (Norway) bronzite (En86 Fs 14 ).

In this paper we report shock results on nine En $86{ }^{F} s_{14}$ samples hot pressed from grains picked from Bamble bronzite. We compare these data with theoretical Hugoniots computed from static compression, ultrasonic, and Brillouin scattering data. Finally, we explore the implications of these data and recent shock measurements on single-crystal forsterite [Jackson and Ahrens, 1979; Watt and Ahrens, 1983] for the composition of the lower mantle.

\section{Experimenta1 Details}

The experiments were carried out in a manner similar to that detailed by Jackson and Ahrens [1979]. The samples, 2.8-3.4 mm thick, were lapped to within $\pm 0.002 \mathrm{~mm}$ of uniform thickness and mounted on $0.4-0.6 \mathrm{~mm}$ thick tantalum or copper driver plates with an array of fused quartz 
TABLE 1. Pyroxene Compositions Calculated From Microprobe Data

\begin{tabular}{|c|c|c|c|}
\hline & \multicolumn{3}{|c|}{ Specimen } \\
\hline & $\begin{array}{c}\text { A } \\
6 \text { points) }\end{array}$ & $\begin{array}{c}\text { B } \\
4 \text { points) }\end{array}$ & $\begin{array}{c}\mathrm{C} \\
10 \text { points) }\end{array}$ \\
\hline Quadrilateral & $\begin{array}{c}99.53 \\
(+0.21)\end{array}$ & $\begin{array}{c}99.82 \\
(+0.05)\end{array}$ & $\begin{array}{c}99.71 \\
(+0.19)\end{array}$ \\
\hline En & $\begin{array}{l}87.98 \\
(+0.88)\end{array}$ & $\begin{array}{c}85.60 \\
(+0.48)\end{array}$ & $\begin{array}{r}85.39 \\
(+0.98)\end{array}$ \\
\hline Fs & $\begin{array}{l}11.46 \\
(+0.88)\end{array}$ & $\begin{array}{l}13.90 \\
( \pm 0.49)\end{array}$ & $\begin{array}{l}14.08 \\
(+0.52)\end{array}$ \\
\hline Wo & $\begin{array}{c}0.56 \\
(+0.04)\end{array}$ & $\begin{array}{c}0.50 \\
(+0.01)\end{array}$ & $\begin{array}{c}0.52 \\
( \pm 0.18)\end{array}$ \\
\hline other & $\begin{array}{c}0.37 \\
(+0.21)\end{array}$ & $\begin{array}{r}0.18 \\
(+0.05)\end{array}$ & $\begin{array}{c}0.29 \\
(+0.19)\end{array}$ \\
\hline $\begin{array}{l}\text { calculated } \\
\text { density, } \mathrm{Mg} / \mathrm{m}^{3}\end{array}$ & 3.288 & 3.309 & 3.310 \\
\hline
\end{tabular}

En, Fs, and Wo denote enstatite, ferrosilite, and wollastonite, respectively.

arrival mirrors. Lexan projectiles with tantalum or copper flyer plates were accelerated in a twostage light-gas gun to velocities between 4.8 and $6.3 \mathrm{~km} / \mathrm{s}$. Projectile velocities were measured using two 15-ns duration flash $X$ ray sources and $0.01 \mu \mathrm{s}$ electronic counters to record the interflash time interval over a path of about $350 \mathrm{~mm}$ immediately in front of the target assembly. Projectile velocity accuracy was $\pm 0.2 \%$. The quart $z$ arrival mirrors were illuminated with a Xenon lamp and observed with TRW image converter streak camera writing at $2 \mathrm{~cm} / \mu \mathrm{s}$. Streak records were calibrated using a modulated laser beam producing timing marks every $162 / 3 \mathrm{~ns}$ on the film. Further details are given by Jackson and Ahrens [1979] and Jeanloz and Ahrens [1980].

Streak records were scanned by a microphotometer and arrival mirror reflection cutoffs were used to compute sample and buffer mirror travel times from linear or quadratic least squares fits to the photometer scans. Corrections were made for projectile tilt and bowing and for nonlinear streak camera writing rate, as needed. These effects are described in detail by Jackson and Ahrens [1979] and Jeanloz and Ahrens [1980]. Sample or buffer shock wave velocities could be determined to within 1-2\%. Hugoniot and partial release state particle velocities, densities, and pressures were calculated using the impedancematching technique and the Riemann integral approximation [Rice et a1., 1958; Lyzenga and Ahrens, 1978; Jackson and Ahrens, [1979]. Tantalum and copper equation of state data were those of McQueen et a1. [1970] and Mitche11 and Nellis [1981], respectively, and fused quartz data were those of Wackerle [1962] and Jackson and Ahrens [1979].

The nine enstatite samples were cut from three aliquots provided by C. G. Sammis. The aliquots had been made by vacuum hot pressing (at $56 \mathrm{MPa}$ and $1400^{\circ}-1450^{\circ} \mathrm{C}$ ) grains picked from Bamble bronzite. Microprobe analyses (by A. Chodos; Si, $\mathrm{Mg}, \mathrm{Fe}, \mathrm{Ca}, \mathrm{Al}, \mathrm{Ti}, \mathrm{Mn}, \mathrm{Cr}, \mathrm{Na}$, analyzed) were used to calculate pyroxene compositions by the method of Papike et al. [1974], Papike and Camer- on [1976], and Papike and White [1979]. Results are given in Table 1, where "quadrilatera1" denotes the percent of the pyroxene that can be assigned a composition within the standard enstatite-ferrosilite-hedenbergite-diopside quadrilateral of the enstatite-ferrosilite-wollastonite ternary diagram. Densities were calculated from the quadrilateral pyroxene compositions. Crystal densities were measured by Archimedes' technique with immersion in toluene and are given in Table 2. Also given are bulk densities based on the mass and measured dimensions of the sample para1lelepipeds. Shots 109, 089, and 095 were prepared from the A specimen; shots 111 and 115 used the $B$ specimen, and shots $135,142,143$, and 144 used the $C$ specimen. There is good agreement between calculated density $\left(3.30 \mathrm{Mg} / \mathrm{m}^{3}\right)$ and measured crystal densities $\left(3.27 \pm 0.01 \mathrm{Mg} / \mathrm{m}^{3}\right)$ for the $\mathrm{A}$ specimens. Agreement is not so good for the $B$ and c specimens (measured density $=3.25 \pm 0.01 \mathrm{Mg} / \mathrm{m}^{3}$ ); however, the crystal density determination eliminates only pore space accessible to the immersion fluid. Accessible porosity ranged from 1.7 to $3.2 \%$ with an average of $2.2 \%$. Actua 1 porosity is higher because of inaccessible pore space and the presence of spherical particles of radii $2 \mu \mathrm{m}$ and less that were uniformly distributed throughout the samples. Microprobe analysis showed that these particles are nearly pure iron produced by reduction of the enstatite [Dehghan-Banadaki, 1983]. Correcting densities in Table 1 for this iron (about $1.5 \%$ by volume from thin-section grain counts) raises the calculated densities to $3.36,3.38$, and $3.36 \mathrm{Mg} / \mathrm{m}^{3}$ for the $\mathrm{A}, \mathrm{B}$, and $\mathrm{C}$ specimens, respectively. This would then increase our estimated porosities based on the calculated densities by a factor of 2, to an average of $4.5 \%$, with a maximum of $6.4 \%$.

\section{Results and Discussion}

Table 2 presents the measured sample densities, projectile velocities, and sample and buffer mirror shock wave velocities, as well as the calculated Hugoniot and partial release states, in order of increasing Hugoniot pressure.

In Figure 1 we plot shock velocity us versus particle velocity $u_{p}$ using the data in Table 2 and previous results. Where no error bars are shown for our data, the errors are less than the size of the plotted squares. We show linear least squares fits to the data of Trunin et a1. [1965] and Simakov and Trunin [1973] for up greater than $2.0 \mathrm{~km} / \mathrm{s}: \mathrm{u}_{\mathrm{s}}=5.11+1.30 \mathrm{u}_{\mathrm{p}} \quad\left(\mathrm{r}^{2} \stackrel{\mathrm{p}}{=} 0.995\right.$, for 4 points $)$ and $u_{s}=4.71+1.31 u_{p}\left(r^{2}=0.998\right.$, for 4 points), respectively, where $r^{2}$ is the correlation coefficient. The data of McQueen et al. [1967] for $u_{p}$ above $2.0 \mathrm{~km} / \mathrm{s}$ are well fit by a line almost identical to that of Simakov and Trunin. The fit to all the present $u_{p}-u_{s}$ data yields $u_{s}=4.20( \pm 1.43)+1.43( \pm 0.34) u_{p}\left(r^{2}=0.84\right)$. This fit is plotted as the heavy solid line in Figure 1. Our data can be better described by two straight lines: $u_{s}=2.72( \pm 0.59)+1.85( \pm 0.14) u_{p}$ $\left(r^{2}=0.99\right)$ and $u_{s}=4.83( \pm 0.42)+1.22( \pm 0.10) u_{p}$ $\left(r^{2}=0.99\right)$. These fits are plotted as light solid lines in Figure 1. The slope of the fit using all our data is similar to that found in previous work. The $f$ it to our data for shots 089 , $095,109,111$, and 115 yields a much steeper slope than previous work, while the slope for 
TABLE 2. Polycrystalline Enstatite Shock Wave Data and Calculated Hugoniot and Partial Release States

\begin{tabular}{|c|c|c|c|c|c|c|c|c|c|c|c|}
\hline \multirow[b]{2}{*}{ Shot } & \multirow[b]{2}{*}{$\stackrel{\rho_{\mathrm{b}} ; 3}{\mathrm{Mg} / \mathrm{m}}$} & \multirow[b]{2}{*}{$\begin{array}{c}\rho_{\mathrm{x}} \\
\mathrm{Mg} / \mathrm{m}^{3}\end{array}$} & \multirow[b]{2}{*}{$\begin{array}{l}u_{\mathrm{fm}}, \\
\mathrm{km}_{\mathrm{s}}\end{array}$} & \multirow[b]{2}{*}{$\begin{array}{l}u_{s}, \\
\mathrm{~km} / \mathrm{s}\end{array}$} & \multirow[b]{2}{*}{$\begin{array}{l}\text { usb, } \\
\mathrm{km} / \mathrm{s}\end{array}$} & \multicolumn{3}{|c|}{ Hugoniot State } & \multicolumn{3}{|c|}{ Partial Release State } \\
\hline & & & & & & $\begin{array}{l}\mathrm{u}_{\mathrm{p}} \\
\mathrm{km} / \mathrm{s}\end{array}$ & $\begin{array}{l}\mathrm{P}, \\
\mathrm{GPa}\end{array}$ & $\begin{array}{c}\rho, \\
\mathrm{Mg} / \mathrm{m}^{3}\end{array}$ & $\begin{array}{l}\mathrm{u}_{\mathrm{p}}, \\
\mathrm{km} / \mathrm{s}\end{array}$ & $\begin{array}{l}\mathrm{P} \\
\mathrm{GPa}\end{array}$ & $\begin{array}{l}\rho, \\
\mathrm{Mg} / \mathrm{m}^{3}\end{array}$ \\
\hline & & & & & & & & & & & \\
\hline & & 6) & & $(+0$. & & & & & & & \\
\hline 144 & & & & & & .94 & & 7 & & $\overline{8} 9.9$ & \\
\hline & & $( \pm 0$. & $( \pm 0.02)$ & $( \pm 0$. & $( \pm 0.05)$ & $( \pm 0.02)$ & $.7)$ & $( \pm 0.036)$ & $\pm 0.03)$ & $( \pm 1.0)$ & $( \pm 0$. \\
\hline 15 & $\begin{array}{r}3.1 \\
+0.0\end{array}$ & $\begin{array}{r}3 . \\
+0 .\end{array}$ & & $\begin{array}{c}10.07 \\
(+0.04)\end{array}$ & $\begin{array}{c}8.87 \\
(+0.06)\end{array}$ & $\begin{array}{r}3.92 \\
(+0.01)\end{array}$ & $\begin{array}{l}1 \overline{25} .1 \\
(+0.7)\end{array}$ & $\begin{array}{r}5.190 \\
(+0.013)\end{array}$ & $\begin{array}{c}4.90 \\
(+0.04)\end{array}$ & $\begin{array}{c}95.7 \\
(+1.4)\end{array}$ & 4. \\
\hline 35 & 3. & & & 9. & & 4.02 & 125.8 & 440 & 4.98 & 98.9 & 4. \\
\hline & $( \pm 0.0$ & $( \pm 0$. & $( \pm 0$ & $( \pm 0$. & $( \pm 0$. & $( \pm 0.01)$ & & $( \pm 0$ & $( \pm 0.07)$ & $( \pm 2.4)$ & $( \pm 0$. \\
\hline 111 & 3.1 & & & 10.27 & & & 134.9 & 326 & & $1 \overline{04.6}$ & \\
\hline 42 & & 3. & & $\frac{+0}{10}$. & $\overline{10}$ & & & & 5.64 & $\frac{( \pm 4.4)}{124.8}$ & \\
\hline & $( \pm 0.02)$ & $( \pm 0.0041)$ & $( \pm 0.01)$ & $( \pm 0$. & $( \pm 0.0$ & $( \pm 0.01)$ & $( \pm 0.6)$ & $( \pm 0$. & $(+0.04)$ & $( \pm 1.8)$ & $( \pm 0$. \\
\hline 089 & $\begin{array}{r}3.2067 \\
+0.0021\end{array}$ & $\begin{array}{c}3.2625 \\
0\end{array}$ & $\begin{array}{r}5.97 \\
(+0.01)\end{array}$ & $\begin{array}{c}\overline{10} .68 \\
(+0.06)\end{array}$ & $\begin{array}{r}9.49 \\
+0\end{array}$ & 4.32 & $1 \overline{4} 8.1$ & & 5.44 & 116.8 & \\
\hline 43 & 3.1 & 3. & -6. & 10 . & 9 & 4.48 & 148 & & & 120.5 & 4.6 \\
\hline & $( \pm 0.026)$ & $( \pm 0.0032)$ & $( \pm 0.01)$ & $( \pm 0.05)$ & $( \pm 0.0$ & $( \pm 0.02)$ & & $( \pm 0$. & $( \pm 0$ & & $( \pm 0$. \\
\hline 095 & 3.2082 & $\begin{array}{r}3.2706 \\
(+0.0032)\end{array}$ & 6.29 & $\overline{11} 1.08$ & $\overline{10} 0.11$ & -4.54 & $1 \overline{6} 1.3$ & 5.434 & 5 & $1 \overline{2} 6.4$ & 4. \\
\hline & & & & & & & & & & & $( \pm 0.345$ \\
\hline
\end{tabular}

$\rho_{b}, \rho_{x}, u_{f p}, u_{s}, u_{s b}$, and $u_{p}$ denote bulk density, crystal density, flyer plate velocity, shock velocity, buffer shock velocity, and particle velocity, respectively.

shots $109,135,142,143$, and 144 is the same as found in previous studies. There is, however, no physical reason to accept the two statistically much superior lines over the fit including a 11 our data.

In Figure 2 we plot our calculated Hugoniot and partial release states as well as the results of Trunin et al. [1965], McQueen et al. [1967], and Jeanloz and Ahrens [1977]. The data have been corrected for porosity [Jeanloz, 1979] and the small quantity of iron impurity. The porosity used was that calculated from the bulk densities in Table 2, with the crystal densities taken as those calculated from the microprobe compositions (Table 1), corrected for the estimated $1.5 \%$ by volume of iron impurities. The zeropressure Gruneisen parameter was taken as 2.0 (E. Knittle, R. Jeanloz, and G. L. Smith, unpublished manuscript, 1985) and $\gamma_{p}$ was assumed constant. Values for this correction ranged from -6.5 to $-9.2 \mathrm{GPa}$; the maximum correction applied is shown on the figure. If $\gamma$ is taken as 1.0 (R.G. McQueen, private communication, 1981), the corrections decrease to between -3.1 and -4.3 $\mathrm{GPa}$.

The iron impurity correction takes account of the compression of the iron impurities, which leads to higher Hugoniot densities than in pure samples. We use the a-iron Hugoniot derived by Jeanloz [1979] for a quadratic us $u_{p}$ relation, assume additivity of iron and enstatite Hugoniots, and find that the presence of $1.5 \%$ by volume of iron increases Hugoniot densities by 0.09 $\mathrm{Mg} / \mathrm{m}^{3}$. This correction also is indicated in $\mathrm{Fig}-$ ure 2 .

our data require a phase change in En 86 at high pressure. Theoretical Hugoniots for the lowpressure phase constructed with a range of first pressure derivatives of the bulk modulus as discussed below are too steep to account for the $\mathrm{Hu}-$ goniot states in the present study and in that of Trunin et a1. [1965] on En 85 above pressures of $60-70 \mathrm{GPa}$. This is in agreement with previous static compression investigations of pyroxenes.

Our data appear to yield two distinct $\mathrm{P}-\mathrm{p}$ trajectories, corresponding to the two statistically excellent fits to the $u_{s}-u_{p}$ data noted in Figure 1. The steeper $u_{s}-u_{p}$ line results in a Hugoniot

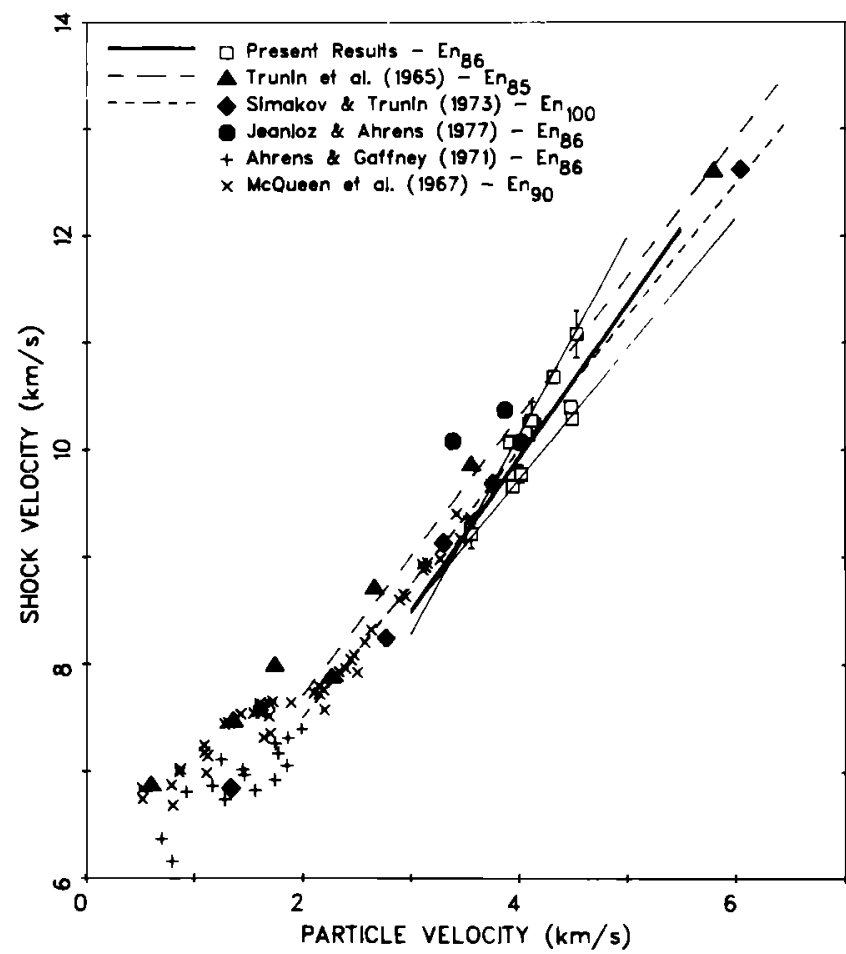

Fig. 1. Enstatite $u_{s}-u_{p}$ data from Table 3 and results from previous studies. The straight lines are least squares fits discussed in the text. 


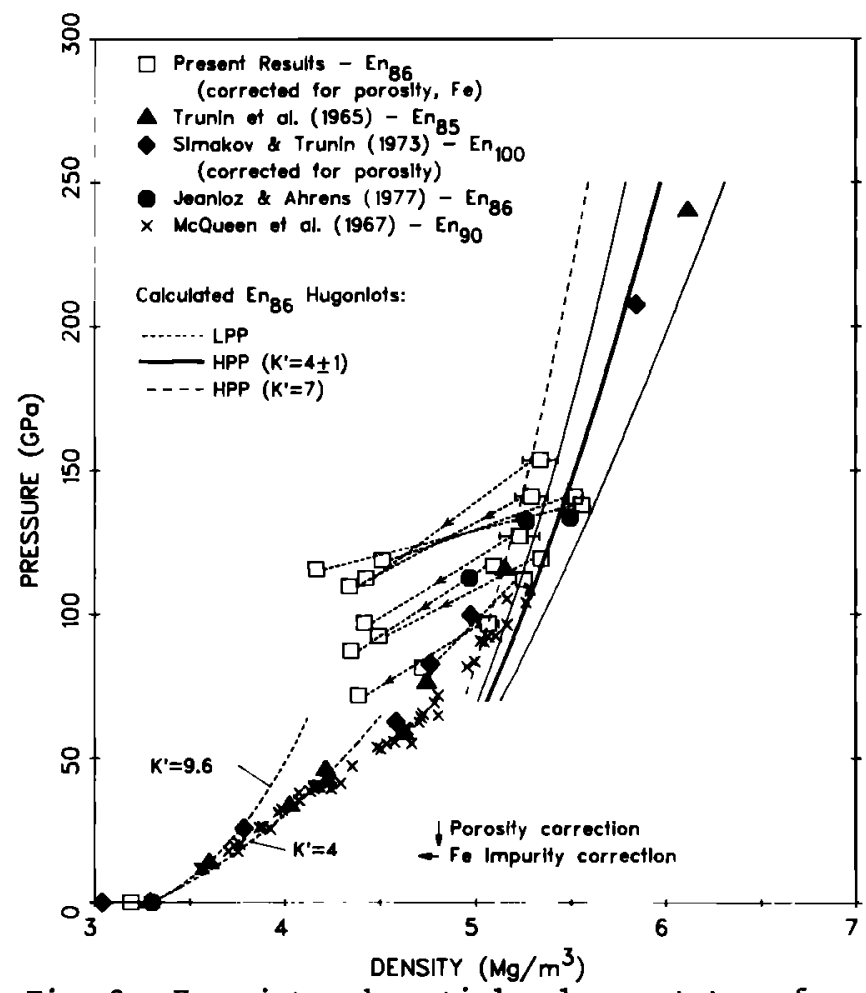

Fig. 2. Hugoniot and partial release states for polycrystalline En 86 compared with previous results. The present data have been corrected for porosity and a small amount of iron impurity. The maximum corrections applied are indicated. Theoretical Hugoniots based on the data in Table 3 are discussed in the text. LPP and HPP denote low- and high-pressure phase, respectively.

steeper and up to $0.25 \mathrm{Mg} / \mathrm{m}^{3}$ less dense than the Hugoniot from the shallower $u_{s}-u_{p}$ line. Experimental errors are not sufficient to explain this difference in $P-p$ trajectories (where no error bars are shown on the Hugoniot states, the errors (Table 2) are smaller than the size of the plotted squares) and neither are the small variations in composition among the three aliquots (Table 1). The results of Jeanloz and Ahrens [1977], a1so for Bamble bronzite (En 86$)$, are likewise ambiguous. The datum at $113 \mathrm{GPa}$ is marginally less dense than any of the present results, whereas of the two data at $133 \mathrm{GPa}$, one agrees well with our lower-density results, while the other matches the denser Hugoniot.

The datum of Trunin et a1. [1965] for En85 at $115 \mathrm{GPa}$ lies midway between our two groups of data, while the point at $240 \mathrm{GPa}$ agrees with our most compressible group of Hugoniot states. The results of Simakov and Trunin [1973] for En 100 are denser than our less compressible Hugoniot but less dense than our higher-density Hugoniot and the data of McQueen et a 1. [1967] for Eng0, as one would expect from the relative iron contents of the three materials. These observations, combined with the fact that the streak records for shots $135,142,143$, and 144 have sharper mirror reflection cutoffs than the previous shots, lead us to regard our denser Hugoniot as more reliable; however, we are not able to justify discarding the lower-density observed Hugoniot states on these grounds alone, and thus we retain them in the discussion below.
The partial release states are consistently much shallower than the Hugoniot, indicating that the samples begin retransforming from the highpressure phase immediately upon release from peak shock pressure. A similar conclusion is reached when release paths are calculated using the new formulation of T.J.Ahrens (unpublished manuscript, 1985), which assumes a quadratic pressure-particle velocity release path rather than the linear path used here.

We now compare our corrected Hugoniot data with theoretical Hugoniots calculated using experimental data for enstatite. Table 3 gives the equation of state (EOS) data we use for the lowand high-presure phase calculated Hugoniots for $\left(\mathrm{Mg}_{0.86}, \mathrm{Fe}_{0.14}\right) \mathrm{SiO}_{3}$. For the low-pressure phase we use the ultrasonic and Brillouin scattering data of Kumazawa [1969] for En 84, Frisillo and Barsch [1972] for En80, and Weidner et al. [1978] for En 100 for the bulk modulus, $K_{0}$. We use two values for $K^{\prime}(=\partial K / \partial P)$, a high value of 9.6 from Frisillo and Barsch [1972], and a more typical value of this parameter, 4.0. The zero-pressure GrUneisen parameter, $\gamma_{0}$, is from Frisillo and Barsch [1972]. We assume that the Grlneisen parameter varies with volume as $\gamma / \gamma_{0}=\left(p_{0} / \rho\right)^{n}$ and take $n=1.5$, with a large uncertainty. Davies [1974] gives typical $n$ values for close-packed oxides. For the high-pressure phase we use $\rho_{0}$, $\mathrm{K}_{\mathrm{o}}$, and $\mathrm{K}^{\prime}$ from the critical compilation of Jean$10 z$ and Thompson [1983]. The value of 4 for $K^{\prime}$ is that assumed in the analysis of static compression data to determine $K_{0}$. Wolf and Jeanloz [1985] calculated thermoelastic properties of $\mathrm{MgSiO}_{3}$ (pv) using a lattice dynamics approach and found a value of 3.8 for $K^{\prime}$. They caution, however, that their study applies to a hypothetical cubic $\mathrm{MgSiO}_{3}$ (pv) structure and not necessarily to the actual distorted phase. The Grllneisen parameter is from analysis of thermal expansion data for ( $\left.\mathrm{Mg}_{0.9}, \mathrm{Fe}_{0.1}\right) \mathrm{SiO}_{3}$ (pv) of $\mathrm{E}$. Knittle, R. Jeanloz, and G. L. Smith (unpublished manuscript, 1985). The best fit to all their data yielded a $r$ of 1.77 , while a fit of the high-temperature data gave a value of 2.20. R.G.McQueen (private communication, 1981) obtained a value of 1.0 from shock wave studies on slightly porous forsterite. We use Jeanloz and Ahrens' [1977] estimate for the transition energy, $E_{t r}$.

We use third-order finite strain theory, relating isentropes and Hugoniots via the Grlineisen parameter; the complete equations are given by Jackson and Ahrens [1979].

The calculated Hugoniots are shown in Figure 2. In the low-pressure phase the shock wave data exhibit higher densities as pressure increases than do the calculated Hugoniots for both values of $\mathrm{K}^{\prime}$, making clear the presence of a phase transformation. For the higher $K^{\prime}$ the mixedphase region begins at between 20 and $25 \mathrm{GPa}$, while for $K^{\prime}=4$ it does not start until about 40 GPa. A recent ultrasonic study of En 80 to $3 \mathrm{GPa}$ by Webb and Jackson [1985] supports Frisillo and Barsch's [1972] value of $K^{\prime}$, yielding a zeropressure $R^{\prime}$ of 11.6 . $K^{\prime \prime}\left(=\partial^{2} \mathrm{~K} / \partial \mathrm{P}^{2}\right)$ was also measured and was found to be negative, reducing $\mathrm{K}^{\prime}$ to 7.2 at $3 \mathrm{GPa}$. In the high-pressure regime, the heavy curve was calculated from the HPP EOS parameters in Table 3 ; the 1 ight curves include the uncertainties in $\rho_{0}, K_{0}$, and $K^{\prime}$.

The Hugoniot states for our group of shots with higher densities, corrected for porosity and 
TABLE 3. Equation of State Parameters

for Low- and High-Pressure Phases of Enstatite, $\left(\mathrm{Mg}_{0.86}, \mathrm{Fe}_{0.14}\right) \mathrm{SiO}_{3}$

\begin{tabular}{|c|c|c|}
\hline & $\begin{array}{c}\text { Low-Pressure } \\
\text { Phase }\end{array}$ & $\begin{array}{c}\text { High-Pressure } \\
\text { Phase (pv) }\end{array}$ \\
\hline $\begin{array}{l}\rho_{0}, \mathrm{Mg} / \mathrm{m}^{3} \\
\mathrm{R}_{0}, \mathrm{GPa}\end{array}$ & $\begin{array}{l}3.30 \\
106 . \\
( \pm 2 .)\end{array}$ & $\begin{array}{l}4.277 \\
262 . \\
( \pm 6 .)\end{array}$ \\
\hline $\mathrm{K}^{\prime}$ 'dimension less & $9.6,4.0$ & $\begin{array}{c}4.0 \\
( \pm 1.0)\end{array}$ \\
\hline $\begin{array}{l}\gamma_{0}, \\
\text { dimension less } \\
n, \\
\text { dimension less } \\
\mathrm{E}_{\mathrm{tr}}, \mathrm{kJ} / \mathrm{g}\end{array}$ & $\begin{array}{c}1.6 \\
( \pm 0.2) \\
1.5 \\
( \pm 0.5) \\
-\end{array}$ & $\begin{array}{c}2.0 \\
(+0.5) \\
1.5 \\
( \pm 0.5) \\
1.6 \\
( \pm 0.5)\end{array}$ \\
\hline
\end{tabular}

iron impurities, are within the band of calculated Hugoniots above pressures of $110 \mathrm{GPa}$. The highest pressure datum of Trunin et a1. [1965] for En85 and that of Simakov and Trunin [1973] for $\mathrm{En}_{100}$ also agree well with the calculated Hugoniots, as does one of the three En 86 data of Jeanloz and Ahrens [1977]. Data of McQueen et al. [1967] for Engo above $95 \mathrm{GPa}$ lie within the bands of theoretical Hugoniots.

The agreement between our lower-density group of shots and the calculated Hugoniots is not so good, especially for the data at pressures of 104,125 , and $135 \mathrm{GPa}$. The experimental uncertainties for the data at 148 and $161 \mathrm{GPa}$ make them only marginally compatible with the lower density end of the range of theoretical Hugoniots. If the Grllneisen parameter is taken as 1.0 based on R.G.McQueen's (private communication, 1981 ) porous forsterite shock wave experiments instead of the 2.0 used here, based on the thermal expansion data of $E$. Knittle, R. Jeanloz, and G. L. Smith (unpublished manuscript, 1985), the lower bound of the range of model Hugoniots is shifted to higher densities (by $0.02 \mathrm{Mg} / \mathrm{m}^{3}$ at 100 $\mathrm{GPa}, 0.08 \mathrm{Mg} / \mathrm{m}^{3}$ at $150 \mathrm{GPa}$, and $0.11 \mathrm{Mg} / \mathrm{m}^{3}$ at 200 $\mathrm{GPa}$ ), and the disagreement is increased.

We include in Figure 2 a calculated HPP Hugoniot with $R^{\prime}=7$. Some support for this value comes from the $\left(\mathrm{Mg}_{0.9}, \mathrm{Fe}_{0.1}\right) \mathrm{SiO}_{3}$ (pv) thermal expansion data of E. Knittie, R. Jeanloz, and G. L. Smith (unpublished manuscript, 1985). When their complete data set was fit as a function of temperature, zero-pressure bulk modulus, molar volume at $0^{\circ} \mathrm{K}$, Debye temperature, and $\mathrm{K}^{\prime}$, the best fit resulted in a $K^{\prime}$ value of 7 . This indirect determination of $\mathrm{K}^{\prime}$ does not provide a particularly strong constraint on this parameter. Nonetheless, the agreement between our lower-density Hugoniot states and this model Hugoniot is very good; however, our higher-density data, and the highest-pressure data of Trunin et a1. [1965] and Simakov and Trunin [1973], and the densest datum of Jeanloz and Ahrens [1977] are not well explained by this curve.

We can simultaneously describe all the avai1able Hugoniot data on enstatite at pressures over $100 \mathrm{GPa}$ (except for the lowest-density datum of Jeanloz and Ahrens [1977] and the highest-density datum of Trunin et a1. [1965]), despite the large scatter in densities, by taking $\mathrm{K}^{\prime}=4.5 \pm 1.0$.

We now compare the present results for ensta- tite and our previous data for forsterite with $P-p$ values for the lower mantle derived by inversion of normal mode and seismic travel time data. In Figure 3 we plot our En86 data (corrected for porosity and iron impurity) and shock data for single-crystal forsterite, Fo, loaded along the three orthorhombic axes [Jackson and Ahrens, 1979; Watt and Ahrens, 1983]. We also include data of McQueen and Marsh [1966] and Marsh [1980] for fayalite, Fa, (Rockport, Massachusetts, $\rho=$ $4.28 \mathrm{Mg} / \mathrm{m}^{3}$ compared with 4.39 for stoichiometric fayalite), for Fo 45 (dunite, Mooihoek Mine, Transvaa 1 [McQueen et a1., 1967]), and for Fo88 (dunite, Twin Sisters Peak, Washington [McQueen et a 1., 1967]). Note that Jackson and Ahrens [1979] incorrectly take Twin Sisters composition as Fog2 rather than Fo88 [Birch, 1960]. We also plot pressure versus density for the Preliminary Reference Earth Mode1, PREM, [Dziewonski and Anderson, 1981] in the lower mantle to the coremantle boundary.

To make a more direct comparison between the shock wave data for forsterite and enstatite, we calculate a Hugoniot for Fo86 by linear interpolation between the Fo100 and Fa data in Figure 3. We use an average Hugoniot for polycrystalline Fo 100 developed by Watt and Ahrens [1983]. The striking linearity of olivine shock properties with iron content is shown by the fact that interpolation between the Fo 100 data and Fo45 data yields virtually the same Fo86 Hugoniot (to within $0.01 \mathrm{Mg} / \mathrm{m}^{3}$ ) as does interpolation between Fo100 and pure Fa. Additionally, our interpolated curve for Fo86 is slightly denser than the Twin Sisters Hugoniot points (Fo88), as one would expect. Recent shock compression data for San Carlos peridot, Fo88, [Furnish and Brown, 1986] at pressures between 100 and $200 \mathrm{GPa}$ agree with our interpolated curve, within the experimental error.

The two groups into which our En 86 Hugoniot data fall (Figure 2) do not allow a simple comparison to be made. On the one hand, our denser Hugoniot data are slightly denser than the interpolated Fo86 Hugoniot because of the presence of $(\mathrm{Mg}, \mathrm{Fe}) \mathrm{O}$ in addition to $(\mathrm{Mg}, \mathrm{Fe}) \mathrm{SiO}_{3}(\mathrm{pv})$ in the Fo 86 high-pressure phase. (Mg,Fe)0 shows only marginal evidence to support the presence of a high-pressure phase [Vassiliou and Ahrens, 1981, 1982]. On the other hand, the lower-density Hugogoniot data are virtually identical to the Fol0o $b$ axis data of Jackson and Ahrens [1979]. This would tend to support our preference for the higher-density En86 data noted earlier, based on the better quality of the shock wave streak camera records. We note, however, that Furnish and Brown's Fo88 data, when plotted in $P-\left(\rho / \rho_{0}\right)$ space, suggest better agreement with Watt and Ahrens' [1983] $\mathrm{Fo}_{100}$ a and $c$ axis data than with Jackson and Ahrens' [1979] b axis data. Obvious$1 y$, further shock compression study of both olivines and pyroxenes is needed to resolve this conflict.

Also included in Figure 3 are calculated Hugoniots for the high-pressure phases of En 86 and Fo86. The EOS data in Table 3 were used for En 86; the Fo 86 curve was calculated using data from Jean $10 z$ and Thompson [1983] for perovskite and ( $\mathrm{Mg}, \mathrm{Fe}) 0$. The error bars include the combined uncertainties in $\rho_{0}, K_{O}$, and $K^{\prime}$. The theoretical Hugoniots suggest that Fo86 is less dense than Eng6 in the lowermost mantle, although given the 


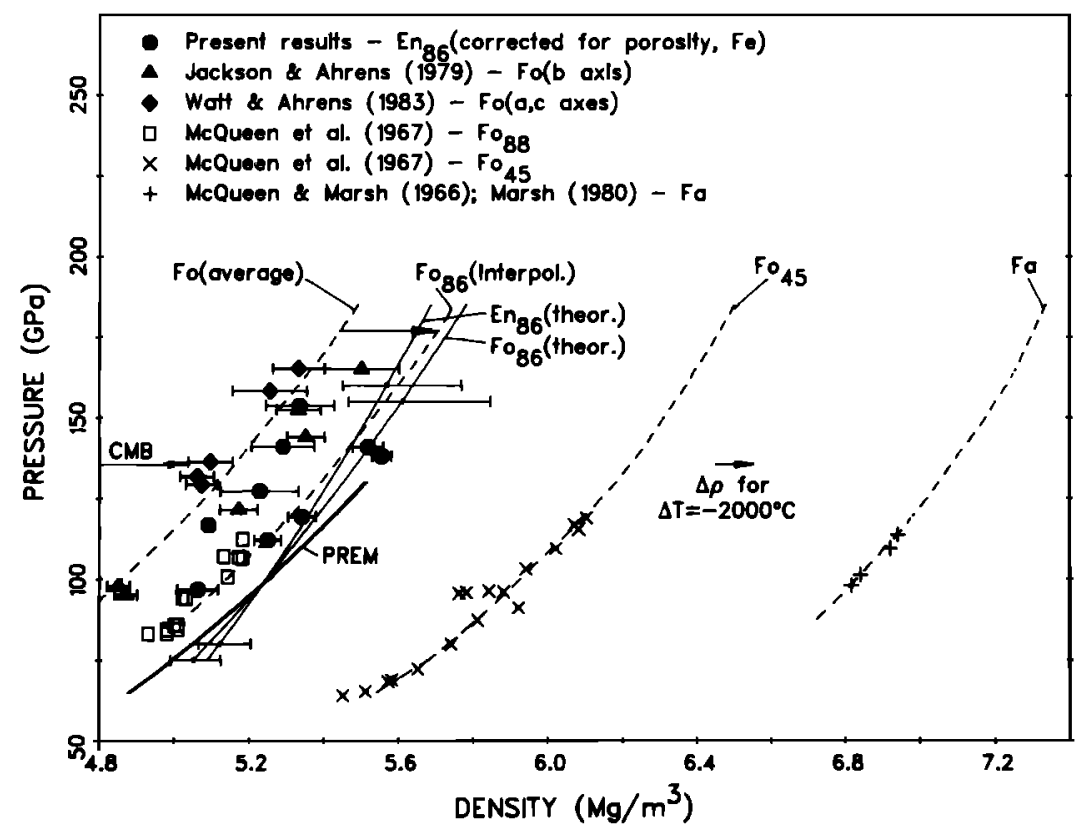

Fig. 3. Shock compression data for olivines and pyroxenes. The Fo86 curve is an interpolation between the average Fo curve of Watt and Ahrens [1983] and Fa data of McQueen and Marsh [1966] and Marsh [1980]. Also plotted are calculated Hugoniots for Fo86 and En86 and the Preliminary Reference Earth Model to the core-mantle boundary (CMB).

uncertainties in the calculated Hugoniots, the difference (less than $0.04 \mathrm{Mg} / \mathrm{m}^{3}$ ) is most likely not significant. The difference between the theoretical Fo86 Hugoniot and the Fo86 Hugoniot interpolated from the experimental shock wave data is $0.11 \mathrm{Mg} / \mathrm{m}^{3}$ at $90 \mathrm{GPa}$ and $0.03 \mathrm{Mg} / \mathrm{m}^{3}$ at 190 GPa. The larger difference at lower pressures may be caused by the small amount of Foloo data and residual influences of the mixed-phase region at these pressures. The theoretical and experimental Hugoniots for Eng6 agree for our denser En86 data, while, as discussed above, a perovskite $\mathrm{K}^{\prime}$ of $4.5 \pm 1.0$ would simultaneously satisfy all our En86 data, within experimental error. Such a $K^{\prime}$ would also improve the agreement between the Fo86 theoretical and interpolated Hugoniots. Given the spread in the theoretical Hugoniots, it is evident that more static compression studies of perovskite structure silicates, especially measurements of $K_{0}$ and $K^{\prime}$, are needed.

our results do not suggest the presence of "post-perovskite" phases of olivines and pyroxenes as proposed by Jeanloz and Ahrens [1977] and Jackson and Ahrens [1979], at least to shock pressures of $160 \mathrm{GPa}$.

Finally, we compare the experimental data for shocked olivines and pyroxenes with the lower mantle density profile of PREM. We note that temperatures reached in shock compression at pressures similar to those in the lower mantle are higher than lower mantle temperature estimates. For example, Stacey [1977] calculated a temperature of $3157^{\circ} \mathrm{K}$ at the core-mantle boundary (CMB) $(P=135 \mathrm{GPa})$. Brown and Shankland [1981] found a value of $2449^{\circ} \mathrm{K}$ in an adiabatic mantle; a superadiabatic contribution estimated to be $200^{\circ} \mathrm{K}$ would increase the temperature at the CMB to $2650^{\circ} \mathrm{K}$. Lyzenga and Ahrens [1980] measured shock temperatures in forsterite single crystals at pressures between 150 and $180 \mathrm{GPa}$ and combining their data with the forsterite Hugoniot temperature calculations of Ahrens et al. [1969], found shock temperatures of $3888^{\circ} \pm 750^{\circ} \mathrm{K}$ at $135 \mathrm{GPa}$. The uncertainty is mainly a result of a range of assumed values for $E_{t r}$, the energy of the phase transition $(1.5 \pm 0.05 \mathrm{~kJ} / \mathrm{mole})$. Thus the shock temperatures measured at pressures equivalent to those at the base of the mantle are $400^{\circ}-1900^{\circ} \mathrm{K}$ higher than those estimated in the lower mantle, and the shock densities are consequently lower than would be found in the earth. Correcting Hugoniot densities for this temperature effect raises the measured densities by at most 0.10 $\mathrm{Mg} / \mathrm{m}^{3}$ for a maximum $2000^{\circ} \mathrm{K}$ reduction in shock temperature. This maximum density correction is indicated in Figure 3.

Taking this maximum density correction into account, we find that our higher-density En 86 and interpolated Fo86 densities are compatible with PREM. When experimental errors are included, our high-density En86 data allow Mg mole fractions, $\mathrm{x}_{\mathrm{Mg}}$, between 0.82 and 0.90 in order to match PREM. On the other hand, our lower-density En86 data require $x_{\mathrm{Mg}}$ between 0.75 and 0.85 . These values are all lower than those of Liu [1977], Watt and $O^{\prime}$ Connell [1978], and Watt and Ahrens [1982], who found $\mathrm{x}^{\mathrm{Mg}}$ 's of 0.90-0.95 in perovskite structure lower mantles with olivine and pyroxene stoichiometries. The very low $\mathbf{x}_{\mathrm{Mg}}$ values inferred using the lower-density Eng6 data provide additional grounds for regarding these data with less confidence than the higher-density results. The theoretical En 86 and Fo 86 Hugoniots are in good agreement with PREM when the uncertainties in the EOS parameters are considered. When a temperature correction is applied to the theoretical curves, a range of $\mathrm{x}_{\mathrm{Mg}}$ between 0.82 and 0.90 is allowed. 
Thus results of the shock wave experiments on olivines and pyroxenes suggest that the lower mantle has an iron content similar to the upper mantle (with $\mathrm{Mg}$ mole fractions between 0.85 and 0.90 ). This contrasts with conclusions of similar, or depleted, lower mantle iron content reached from consideration of static compression data on olivines and pyroxenes. More shock and static compression studies of the high-pressure properties of olivines and pyroxenes are needed to resolve this difference.

\section{Conclusions}

We have reported shock compression results at pressures from 104 and $161 \mathrm{GPa}$ for hot-pressed Bamble bronzite (En 86 ). The shock velocity-particle velocity data can be described by a straight line in $u_{s}{ }^{-u_{p}}$ space with slope similar to slopes derived from the limited data of previous studies on En85 and En 100 . Significantly better fits are obtained when the data are treated in two separate groups, but there is no physical reason for doing so. When compared to lower particle velocity data of McQueen et a1. [1967] for Engo, our $u_{s}-u_{p}$ regults support formation of a high-pressure phase.

In $P-p$ space the data fall along two distinct trajectories (Figure 2). Experimental errors and small differences in composition of the samples are insufficient to account for the spread in data. On the basis of the quality of the streak camera records, agreement with the lower-pressure data to $109 \mathrm{GPa}$ of McQueen et a 1. [1967] for Engo and agreement with models of the lower mantle based on static compression data, we prefer the data lying at higher Hugoniot densities; however, these reasons are not sufficiently compelling to allow us to reject categorically the lower-density group of data. The reason for this behavior is not understood. We note that the two highestpressure data, at $133 \mathrm{GPa}$, of Jeanloz and Ahrens [1977], also for Bamble bronzite, fall one each on the two $P-p$ curves observed in the present experiments.

We have compared our Hugoniot data to computed Hugoniots for En 86 in the perovskite structure constructed from static compression, ultrasonic, and Brillouin scattering data. When uncertainties in the equation of state parameters are considered and corrections for up to $5 \%$ porosity and $1.5 \%$ by volume metallic iron are applied, we find that the theoretical Hugoniot agrees with the higher density Ens6 data; our lower-density data are only marginally compatible with the theoretical curve. All our En 86 data can be simultaneous$1 y$ satisifed by taking the $K^{\prime}$ of perovskite as $4.5+1.0$. Because the density spread in the theoretical Hugoniot is large, refinement of the static compression data, particularly $K_{0}$ and $K^{\prime}$, for perovskite structure silicates is important to enable more detailed comparison of static and dynamic compression experimental data on pyroxenes.

We have compared our Ens6 data and shock data for sing le-crystal forsterite [Jackson and Ahrens, 1979; Watt and Ahrens, 1983] with the PREM density profile in the lower mantle. An interpolated Fo86 Hugoniot based on an average polycrystalline Fo100 Hugoniot derived from the singlecrysta 1 Foloo data and on results of McQueen et a 1. [1967] and Marsh [1980] for Fa5s and Fa agrees with our higher-density En86 data. Taking account of differences between shock temperatures and lower mantle temperature estimates, we find that an olivine or pyroxene stoichiometry lower mantle with $\mathrm{Mg}$ mole fraction from 0.82-0.90 is compatible with PREM densities; the lower-density En86 data imply $x_{\mathrm{Mg}}$ values between 0.75 and 0.85 .

Acknowledgments. We appreciate the careful construction and execution of the experiments by E. Gelle and M. Long. C. G. Sammis kindly made available samples of his Bamble bronzite. J. J. Papike supplied a copy of his pyroxene composition calculation program. We acknowledge useful discussions with J. M. Vizgirda and helpful comments from E. S. Gaffney and an anonymous reviewer. Computing support was provided by the office of Computer Services and the Department of Geology, Rensselaer Polytechnic Institute. Supported by National Science Foundation grant EAR 8018819. Contribution 4019, Division of Geological and Planetary Sciences, California Institute of Technology.

\section{References}

Ahrens, T. J., and E. S. Gaffney, Dynamic compression of enstatite, J. Geophys. Res., 76, 5504-5513, 1971 .

Ahrens, T. J., and C. F. Petersen, Shock wave data and the study of the earth, in The Application of Modern Physics to the Earth and Planetary Interiors, edited by S. K. Runcorn, PP. 449-461, John Wiley, New York, 1969.

Ahrens, T. J., D. L. Anderson, and A. E. Ringwood, Equations of state and crystal structures of high-pressure phases of shocked silicates and oxides, Rev. Geophys., 7, 667-707,1969.

Ahrens, T. J., J. H. Lower, and P. L. Lagus, Equation of state of forsterite, J. Geophys. Res., 76, 518-528, 1971 .

Birch, F., The velocity of compressional waves in rocks to 10 kilobars, 1 , J. Geophys. Res., 65, 1083-1102, 1960 .

Brown, J. M., and T. J. Shankland, Thermodynamic parameters in the earth as determined from seismic profiles, Geophys, J. R. Astron. Soc., $66,579-596,1981$

Davies, G. F., Limits on the constitution of the lower mant le, Geophys. J. R. Astron. Soc., 38, $479-503,1974$.

Dehghan-Banadaki, A., High pressure deformation of hot-pressed polycrystalline orthoenstatite, Ph.D. thesis, Univ. South. Calif., Los Angeles, 1983.

Dziewonski, A. M., and D. L. Anderson, Preliminary reference earth model, Phys. Earth Planet. Inter., 25, 297-356, 1981

Frisillo, A. L., and G. R. Barsch, Measurement of single-crystal elastic constants of bronzite as a function of pressure and temperature, $\mathrm{J}$. Geophys. Res., 77, 6360-6384, 1972.

Furnish, M. D., and J. M. Brown, Shock loading of single-crysta1 olivine in the 199-200 range, J. Geophys. Res., in press, 1986 .

Ito, E., The absence of oxide mixture in highpressure phases of Mg-silicates, Geophys. Res. Lett., 4, 72-74, 1977 .

Jackson, I., and T. J. Ahrens, Shock wave compression of single-crystal forsterite, J. Geophys. Res., 84, 3039-3048, 1979. 
Jakubith, M., and P. Seidel, Shock-loading experiments on eclogite, Geophys. Res. Lett., $\underline{9}$, 408-411, 1982 .

Jeanloz, R., Properties of iron at high pressures and the state of the core, J. Geophys. Res., 84, 6059-6069, 1979.

Jeanloz, R., Shock effects in olivine and implications for Hugoniot data, J. Geophys. Res., $85,3163-3176,1980$.

Jeanloz, R., and T. J. Ahrens, Pyroxenes and olivines: Structural implications of shock wave data for high-pressure phases, in High-Pressure Research: Applications in Geophysics edited by M. H. Manghnani and S. Akimoto, Pp.439461, Academic, Orlando, Fla., 1977.

Jeanloz, R., and T. J. Ahrens, Release adiabat measurements on minerals: The effect of viscosity, J. Geophys. Res., 84, 7545-7548, 1979.

Jeanloz, R., and T. J. Ahrens, Equations of state of $\mathrm{FeO}$ and $\mathrm{CaO}$, Geophys. J. R. Astron. Soc., $62,505-528,1980$.

Jeanloz, R., and A. B. Thompson, Phase transitions and mantle discontinuities, Rev. Geophys., 21, 51-74. 1983.

Jeanloz, R., T. J. Ahrens, J. S. Lally, G. L. Nord, J. M. Christie, and A. H. Heuer, Shockproduced olivine glass: First observation, Science, 197, 457-459, 1977.

Kumazawa, M., The elastic constants of singlecrystal orthopyroxene, J. Geophys. Res., 74, 5973-5980, 1969.

Liu, L. G., Post-oxide phases of forsterite and enstatite, Geophys. Res. Lett., 2, 417-419, 1975.

Liu, L. G., The post-spinel phase of forsterite, Nature, 262, 770-772, 1976a.

Liu, L. G., Orthorhombic perovskite phases observed in olivine, pyroxene, and garnet at high pressures and temperatures, Phys. Earth planet. Inter., $11,289-298,1976 \mathrm{~b}$.

Liu, L. G., Mineralogy and chemistry of the earth's lower mantle above $1000 \mathrm{~km}$, Geophys. J. R. Astron. Soc., 48, 53-62, 1977.

Lyzenga, G. A., and T. J. Ahrens, The relation between the shock-induced free-surface velocity and the postshock specific volume of solids, J. Appl. Phys., 49, 201-204, 1978.

Lyzenga, G. A., and T. J. Ahrens, Shock temperature measurements in $\mathrm{Mg}_{2} \mathrm{SiO}_{4}$ and $\mathrm{SiO}_{2}$ at high pressures, Geophys. Res. Lett., I, 141-144, 1980 .

Mao, H. K., T. Yagi, and P. M. Bell, Mineralogy of the Earth's deep mantle: Quenching experiments on mineral compositions at high pressure and temperature, Year Book Carnegie Inst. Washington, 1976, 502-504, 1977.

Marsh, S. P., Shock Hugoniot Data, University of California Press, Berkeley, 1980 .

McQueen, R. G., The equation of state of mixtures, alloys, and compounds, in Seismic Coupling Advanced Research Project Meeting, edited by G. Simmons, Pp. 53-106, National Technical Information Service, Springfield, Va., 1968.

McQueen, R. G., and S. P. Marsh, in Handbook of Physical Constants, edited by S. P. Clark, Mem. Geol. Soc. Am, 97, 156, 1966.

McQueen, R. G., S. P. Marsh, and J. N. Fritz, Hugoniot equation of state of twelve rocks, J. Geophys. Res., 72, 4999-5036, 1967.
McQueen, R. G., S. P. Marsh, J. W. Taylor, J. N. Fritz, and W. J. Carter, The equation of state of solids from shock wave studies, in High Velocity Impact Phenomena, edited by $R$. Kinslow, pp. 294-419 and appendices, Academic, Orlando, Fla., 1970.

Mitche11, A. C., and W. J. Ne1lis, Shock compression of aluminum, copper, and tantalum, $J$. App1. Phys., 52, 3363-3374, 1981 .

Papike, J. J., and M. Cameron, Crystal chemistry of silicate minerals of geophysical interest, Rev. Geophys., 14, 37-80, 1976.

Papike, J. J., and C. White, Pyroxenes from planetary basalts: Characterization of "other" than quadrilateral components, Geophys. Res. Lett., 6, 913-916, 1979.

Papike, J. J., K. L. Cameron, and R. Baldwin, Amphiboles and pyroxenes: Characterization of other than quadrilateral components and estimates of ferric iron from microprobe data, Geo1. Soc. Am. Abstr. Programs, \#6, 1053-1054, 1974 .

Rice, M. H., R. G. McQueen, and J. M. Walsh, Compression of solids by strong shock waves, Solid State Phys, 6 , 1-63, 1958.

Sawamoto, H., Orthorhombic perovskite $(\mathrm{Mg}, \mathrm{Fe}) \mathrm{SiO}_{3}$ and the constitution of the lower mantle, in High Pressure Research: Applications in Geophysics, edited by M. H. Manghnani and S. Akimoto, Pp. 219-244, Academic, Orlando, Fla., 1977.

Simakov, G. V., and R. F. Trunin, On the existence of the overdense perovskite structures in magnesium silicates under conditions of high pressure, Izv. Acad. Sci. USSR Phys. Solid Earth, Eng1. Trans., no.9, 603-604, 1973.

Stacey, F. D., A thermal model of the earth, Phys. Earth Planet. Inter., 15, 341-348, 1977.

Syono, Y., T. Goto, J.-I. Sato, and H. Takei, Shock compression measurements of singlecrystal forsterite in the pressure range 15-93 $\mathrm{GPa}, \mathrm{J}$. Geophys. Res., $\underline{86}, 6181-8186,1981 \mathrm{a}$.

Syono, Y., T. Goto, H. Takei, M. Tokonami, and K. Nobugai, Dissociation reaction in forsterite under shock compression, Science, 214, 177$179,1981 \mathrm{~b}$.

Trunin, R. F., V. I. Gon'shakova, G. V. Simakov, and N. E. Galdin, A study of rocks under the high pressures and temperatures created by shock compression, Izv. Acad. Sci. USSR Phys. Solid Earth, Eng1. Trans., no.8, 579-586, 1965 .

Vassiliou, M. S. and T. J. Ahrens, Hugoniot equation of state of periclase to $200 \mathrm{GPa}$, Geophys. Res. Lett., $\underline{8}, 729-732,1981$.

Vassiliou, M. S., and T. J. Ahrens, The equation of state of ( $\left.\mathrm{Mg}_{0.6} \mathrm{Fe}_{0.4}\right) 0$ to $200 \mathrm{GPa}$, Geophys. Res. Lett., $9,127-130,1982$.

Wackerle, J., Shock wave compression of quartz, J. App1. Phys., 33, 922-937, 1962.

Wat $t, J . P .$, and $T$. J. Ahrens, The role of iron partitioning in mantle composition, evolution, and scale of convection, J. Geophys. Res., 87, $5631-5644,1982$.

Watt, J. P., and T. J. Ahrens, Shock compression of single-crystal forsterite, J. Geophys. Res., 88, 9500-9512, 1983 .

Watt, J. P., and R. J. O'Connell, Mixed-oxide and perovskite-structure model mantles from 700- 
$1200 \mathrm{~km}$, Geophys. J. R. Astron. Soc., 54, $610-630,1978$.

Webb, S. L., and I. Jackson, The anomalous pressure dependence of the elastic moduli for single-crystal orthopyroxene (abstract), EфS Trans. AGU, 66, 371, 1985.

Weidner, D. J., H. Wang, and J. Ito, Elasticity of enstatite, Phys. Earth Planet. Inter., 17, P7-P13, 1978.

Wolf, G. H., and R. Jeanloz, Lattice dynamics and structural distortions of $\mathrm{CaSiO}_{3}$ and $\mathrm{MgSiO}_{3}$ perovskites, Geophys. Res. Lett., 12, 413-416, 1985 .
Yagi, T., H. R. Mao, and P. M. Bell, Crystal structure of $\mathrm{MgSiO}_{3}$ perovskite, Year Book Carnegie Inst. Washington, 1976, 516-519, 1977.

T. J. Ahrens, Seismological Laboratory, California Institute of Technology, Pasadena, CA 91125.

J. P. Watt, Department of Geology, Rensselaer Polytechnic Institute, Troy, NY 12181.

(Received March 21, 1984;

revised October 21, 1985 ;

accepted February 13,1986.) 